De Menezes, U. G. (2018). Consumo colaborativo: um caminho para o desenvolvimento sustentável? Consumer Behavior Review, 2(Special Edition), 56-68.

ISSN: 2526-7884

Editor: Prof. Dr. Marconi Freitas da Costa

Email da revista: cbr@ufpe.br
Avaliação: Double blind review

Recebido: 02 de Maio de 2018

Aceito: 19 de Agosto de 2018

\title{
CONSUMO COLABORATIVO: UM CAMINHO PARA O DESENVOLVIMENTO SUSTENTÁVEL?
}

Uiara Gonçalves de Menezes

Uiara Gonçalves de Menezes é Professora e Pesquisadora do Centro Universitário da Serra Gaúcha. Email: uiara.menezes@gmail.com. A autora agradece aos avaliadores pelos comentários para melhoria do artigo.

\begin{abstract}
Resumo
Dentre as várias propostas para se reduzir os impactos negativos causados pelo homem ao planeta tem se destacado, recentemente, o consumo colaborativo. Este, pode ser definido como um modelo de negócios mediado pelas tecnologias de informação e comunicação que se baseia na colaboração de fornecedores e consumidores (De Menezes, 2016). Partindo desse contexto, este estudo se propôs a identificar, empiricamente, a relação existente entre consumo colaborativo e desenvolvimento sustentável a partir das seguintes ênfases: necessidades humanas, preservação dos recursos e orientação cultural de valor. Para isso foi estudado um caso de uma comunidade virtual de troca de tempo (Bliive). Foram coletados dados de usuários, de um dos gestores e do próprio site do Bliive. Os resultados encontrados permitem observar apenas uma certa relação entre os temas, pois o Bliive não contemplou todas as dimensões do desenvolvimento sustentável (necessidades humanas, preservação do meio ambiente e a preocupação com o futuro). Isso se deu em função dos aspectos ambientais necessários para promover alterações dos padrões de consumo não serem contemplados nos resultados. O destaque é dado para a dimensão dos aspectos sociais relacionados à satisfação das necessidades humanas, tais como participação, afeição, entendimento, proteção, identidade, liberdade e criação, e, por fim, a orientação para a coletividade foi destacada.

Palavras-chave: Desenvolvimento sustentável, Consumo colaborativo, Bliive.
\end{abstract}

Esta obra está licenciada com uma Licença Creative Commons Atribuição 4.0 Internacional.

\section{INTRODUÇÃO}

No desenvolvimento sustentável busca-se atender as necessidades do presente sem comprometer a habilidade das futuras gerações de atender suas próprias necessidades (WCED, 2018).
Corroborando, o $12^{\circ}$ objetivo para o Desenvolvimento Sustentável (PNUD, 2018) destaca a importância de "assegurar padrões de produção e de consumo sustentáveis". Desta forma, as mudanças necessárias envolvem difíceis 
e imprescindíveis escolhas para se mover do discurso para a ação (Drexhage \& Murphy, 2010), e é nesse momento que a ação humana toma um papel fundamental, pois é quando se fala sobre a redução dos níveis de consumo que o comportamento humano é o principal agente.

Algumas práticas dos consumidores são apresentadas na literatura sob diversos conceitos e formas, como por exemplo a resistência ao hiperconsumo (Albinsson, Wolf \& Kopf, 2010), consumo verde (Jansson, Marell \& Nordlund, 2010; Sparks \& Shepherd, 1992), a adoção de práticas de anticonsumo (Black \& Cherrier, 2010), a participação em mercados alternativos (Albinsson \& Perera, 2012), dentre outros.

A economia colaborativa também surge como um caminho. Definida como um modelo de negócios econômico-tecnológico emergente alimentado pelo desenvolvimento simultâneo de tecnologias de informação e comunicação e pela a crescente conscientização dos consumidores, comunidades colaborativas na web de comércio e compartilhamento social (Hamari, Sjöklint \& Ukkonen, 2016), a Collaborative Economy (Economia Colaborativa) pode ser vista como um incentivo ao acesso em detrimento da propriedade, permitindo a presença de redes descentralizadas (ou seja, contato direto entre as pessoas, através de plataformas peer-to-peer). Além disso, tem potencial de desaprisionar a riqueza, com ou sem envolvimento de dinheiro.

Outro ponto destacado, refere-se ao surgimento de novos mercados que, em alguns casos, desafiam as formas tradicionais de fazer negócios, como as regras de mercado e legislação, ao permitir a reutilização de ativos ociosos (Stokes et al., 2014). Quatro distintas formas são contempladas por esse modelo de negócios: Financiamento Colaborativo, Aprendizagem Colaborativa, Produção Colaborativa e o Consumo Colaborativo (Stokes et al., 2014). O consumo colaborativo emerge com a missão de alterar os padrões atuais de consumo, focando no alcance de níveis de consumo mais sustentáveis, envolvendo a construção de relações entre diversos setores sociais, como produtores, comerciantes e consumidores (De Menezes, 2016).

A partir da relação teórica apresentada entre os temas do Consumo Colaborativo e Desenvolvimento Sustentável, questiona-se: como será que essa ligação se dá na prática? Como as organizações que trabalham com Consumo Colaborativo apresentam a integração entre os temas? Seus consumidores percebem algum tipo de relação entre o consumo colaborativo $\mathrm{e}$ a perspectiva sustentável? Com base nesses questionamentos o presente artigo buscou identificar de que forma o Consumo Colaborativo se relaciona com o desenvolvimento sustentável a partir de um caso de organização colaborativa existente no Brasil.

Os objetivos que orientaram a condução deste estudo foram: a) identificar quais satisfatores são encontrados com relação as necessidades humanas; b) levantar aspectos de preservação dos recursos naturais encontrados; e c) avaliar a orientação individualista-coletivista, baseada orientação cultural de valor dos consumidores que se faz presente no caso estudado. Tais objetivos foram selecionados considerando desenvolvimento sustentável como aquele que busca atender as necessidades do presente (satisfatores das necessidades humanas) sem comprometer (preservação dos recursos naturais) a habilidade das futuras gerações de atender suas próprias necessidades (orientação individualistacoletivista).

A organização selecionada para compor este o caso foi o Bliive, que se trata de um banco de tempo viabilizado por meio de uma plataforma online, que foca na troca de talentos, habilidades e conhecimentos entre pessoas.

\section{DESENVOLVIMENTO SUSTENTÁVEL}

Bolis, Morioka e Sznelwar (2014) veem a inseparabilidade entre as dimensões da sociedade e da natureza, e entendem que os recursos naturais representam a base fundamental para satisfazer as necessidades humanas, sendo, neste caso, primordiais para que os direitos da sociedade sejam atendidos. Independente de uma ordem, Mebratu (1998) sintetiza que os diferentes ensinamentos religiosos, filosofias e crenças tradicionais, grandes repositórios de conhecimento humano, juntamente com a ciência moderna, são orientados para a vida em harmonia com a natureza e uns com os outros. A partir dessa ideia central se assenta a essência lógica do que se chama de sustentabilidade.

Desenvolvimento sustentável é um processo de mudança no qual a exploração dos recursos, a direção dos investimentos, a orientação do desenvolvimento tecnológico e a mudança institucional estão todos em harmonia, melhorando $\mathrm{o}$ potencial atual $\mathrm{e}$ futuro em atender às necessidades e aspirações humanas (WCED, 2018). Essa mudança passa, fundamentalmente, 
pela mudança no comportamento do consumidor, ou seja, na forma como este acessa, utiliza e descarta o objeto do seu consumo.

Muitos consumidores, cada vez mais, estão se voltando para formas alternativas de consumo sustentável (Albinsson \& Perera, 2012; Albinsson et al., 2010; Ozanne \& Ballantine, 2010). Nesse contexto que o consumo colaborativo tem se destacado, como uma possível forma de consumo que possa contribuir com o desenvolvimento sustentável, ao passo em que suplanta o hiperconsumo e cria modelos de negócios inovadores fundamentados no compartilhamento (Botsman \& Rogers, 2011).

\section{A visão de homem e o desenvolvimento sustentável}

Um modelo conceitual que englobe a preservação dos recursos naturais e necessidades humanas (incluindo as necessidades econômicas) é o que melhor representa o desenvolvimento sustentável. Contudo, não se pode deixar de inserir nessa combinação, a intenção do agente, visto que é este que irá dar sentido a ação, conforme salienta Leff (2001).

A relação do homem com a natureza pode se resumir em duas dimensões, uma antropocêntrica e, no outro extremo, uma ecocêntrica. O antropocentrismo no desenvolvimento sustentável destaca o papel do ambiente como fonte para a manutenção ou melhoria da qualidade de vida dos seres humanos e, dado o seu valor, precisa ser protegido. Dessa forma, a satisfação das necessidades humanas é a razão para o qual a humanidade deve preservar os recursos naturais (Thompson \& Barton, 1994).

Diferentemente do antropocentrismo, no ecocentrismo os indivíduos valorizam a natureza devido ao seu valor intrínseco, preservando-a por ela própria. Os indivíduos acreditam que o ambiente deve ser protegido pelo valor transcendental (Thompson \& Barton, 1994). Logo, a preocupação ambiental e o interesse na preservação dos recursos são importantes em ambos modos, mas os motivos pelos quais as ações são tomadas é que se distinguem. No antropocentrismo, o conforto, a saúde e a qualidade de vida são as razões pelas quais se deve preservar dos recursos naturais e o ecossistema saudável.

A poluição do ar pode levar a problemas respiratórios, a destruição das florestas pode excluir a possibilidade do desenvolvimento de novos medicamentos, o esgotamento dos combustíveis fósseis e da água podem resultar em uma diminuição do padrão de vida e impactos econômicos consideráveis, por exemplo.

Independentemente das implicações sócio econômicas e de estilos de vida, a conservação da natureza, para os ecocêntricos, tem uma dimensão espiritual e um valor intrínseco que se reflete nas experiências com a natureza e sentimentos sobre ambientes naturais. A ligação entre os seres humanos e a natureza transcende a capacidade de recursos naturais em satisfazer necessidades humanas.

Bolis et al. (2014) compreendem que as dimensões do desenvolvimento sustentável abarcam, além dos aspectos da antropocêntricos da satisfação das necessidades humanas (incluindo aspectos sociais e econômicos) e da preservação dos recursos naturais no longo prazo (considerando limitações explícitas da Terra), uma perspectiva de tomada de decisões, a partir de um ponto de vista axiológico. Assim, a ação balizada no desenvolvimento sustentável tem poder de melhorar o bem-estar da sociedade como um todo (abarcando as gerações futuras), pois apresenta a tomada de decisão ponderada pelas limitações de recursos ambientais e pela qualidade de vida das gerações que estão por vir.

As decisões dos indivíduos estão situadas em um contínuo, onde em um extremo está a perspectiva mais individual e funcionalista, preocupada com questões mais objetivas, orientadas para o racional e para o curto prazo. Já no extremo, está perspectiva considerada oposta, onde destacam-se os aspectos mais subjetivos, do emocional e do longo prazo, baseados em valores sistêmicos e intergeracionais, ou seja, trata-se de uma visão mais coletiva. Esta perspectiva última promove iniciativas que são baseadas em valores sociais, éticos, cooperação, igualdade e equidade (Bolis et al., 2014; Earle \& Gibson, 1998).

Nesse sentido, o desenvolvimento sustentável implica mudar a perspectiva humana de individual para coletiva na tomada de decisões, embasado em valores humanos e éticos, pois as consequências de decisões tomadas por alguns indivíduos podem ser percebidas por outras pessoas que não foram sequer consideradas no processo de tomada de decisão. Essas interdependências tornam mais difícil de, adequadamente, definir o problema e propor soluções eficazes para os dilemas do desenvolvimento sustentável.

Para o desenvolvimento sustentável são considerados, tanto a intensidade de preocupação 
atribuída aos recursos naturais utilizados para o desenvolvimento da sociedade, quanto o grau de coletividade nas decisões sobre o uso destes recursos. Deste modo, tem-se os objetivos norteando as ações, e como resultados, um consumo mais consciente por parte de todos.

As orientações culturais de valor (individualista-coletivista) que se fazem presentes nesse modelo são determinantes para o alcance dos objetivos. Para objetivos mais sustentáveis e consumo consciente, tais como a redução dos impactos sociais e ambientais, é necessário um trabalho em conjunto e a "coletividade pode ser baseada em uma relação normativa que se forma como resultado de valores e normas compartilhadas entre indivíduos unidos por objetivos comuns, interesses e compromissos mútuos" (Earley \& Gibson, 1998, p. 266).

Para promover soluções para o desenvolvimento sustentável, a participação da sociedade desempenha um papel fundamental, destacando a importância dos meios de comunicação na difusão de informações e construção de grupos de pesquisa integrados, bem como a mobilização popular e ação direta. A ação humana oscila em um contínuo entre bem-estar socioeconômico e preocupações ambientais. Abordagens possíveis para os problemas relacionados com o desenvolvimento sustentável começam com o status quo, que se deslocam para a reforma e terminam com a transformação. Existe uma necessidade para a transformação real ou pelo menos por algum tipo de reforma para construir uma sociedade mais sustentável, considerando-se valores fundamentais como a proteção ambiental, justiça e equidade (Hopwood, Mellor \& O'brien, 2005).

Além da visão do homem tem-se também uma visão mais gerencial, onde se pode visualizar as práticas realizadas pelas organizações na busca de um mundo mais sustentável, conforme discutido na próxima seção.

\section{As empresas e o desenvolvimento sustentável}

Uma série de práticas e técnicas podem ser aplicadas pelas empresas para mitigar seus impactos no ambiente natural. Nesse estudo serão discutidas duas práticas gerenciais: Análise do ciclo de vida (ACV) e 3 R's (reduzir, reutilizar e reciclar).

A análise do ciclo de vida dos produtos, pressupõe que todos os produtos desempenham um comportamento previsível em relação às suas vendas. De forma ampla, o ciclo de vida se visualiza em quatro estágios: introdução, crescimento, maturidade e declínio (Kayo, Kimura, Martin \& Nakamura, 2006).

Numa situação aplicada, pode-se utilizar o ciclo de vida como uma técnica para avaliação dos potenciais impactos associados ao ciclo de vida de um produto, processo ou serviço. Essa técnica engloba desde a extração de matérias-primas, transporte, produção, distribuição, utilização, até sua destinação final, que pode ser reciclagem ou descarte. No contexto global busca melhorar o desempenho e a sustentabilidade ambiental dos sistemas de produção, partindo de uma visão muito completa de todo o seu ciclo de vida (IBICT, 2018).

Como visto, a análise do ciclo de vida não se restringe apenas a produtos. Ela pode alcançar dimensões mais amplas e seus conceitos podem ser aplicados a empresas e até a setores. Supõe-se que o ciclo de vida de um setor é resultado da agregação dos ciclos de vida das empresas que o compõem (Kayo et al., 2006).

O aumento do ciclo de vida dos produtos, através do aumento da vida útil dos bens, da diminuição da obsolescência planejada, da recuperação dos bens deteriorados e da reutilização de bens descartados são estratégias que contribuem com o desenvolvimento sustentável.

Outra prática refere-se à linha dos 3R's, reduzir, reutilizar e reciclar destaca-se como aspecto importante na contribuição do desenvolvimento sustentável.

A prática de redução significa minimizar os altos padrões de consumo por parte dos consumidores, tanto quanto de indústrias e demais organizações, através de diminuição das compras, bem como preferência por produtos que apresentam maior eficiência na utilização de água, energia, e liberam menos gases causadores do efeito estufa. Adquirir produtos mais duráveis e menos descartáveis e optar por produtos com menos embalagem são práticas que contribuem para um estilo de vida com menor impacto prejudicial para o mundo.

A redução do consumo deve ser priorizada sobre a reutilização e reciclagem, mas recorre-se à segunda quando já não se tem mais opções com relação à redução. A reutilização envolve 0 aproveitamento dos resíduos sólidos sem a sua transformação biológica, físico-química ou física, de acordo com a Política Nacional dos Resíduos Sólidos (PNRS), Lei N ${ }^{\circ}$ 12.305/Agosto de 2010 
(BRASIL, 2018). Exemplos de práticas que envolvem a reutilização podem ser: usar os dois lados do papel, doar objetos e roupas que não serão mais utilizados, reutilizar caixas e embalagens de plástico e vidro, dentre outras.

Além da redução do consumo e da reutilização, há a reciclagem. De acordo com a mesma lei, da PNRS, reciclar é um processo de transformação dos resíduos sólidos que envolvem a transformação biológica, físico-química ou física das propriedades dos produtos, com objetivo de transformá-los em novos insumos ou novos produtos.

Os objetivos da utilização dos 3R's focam na redução da geração de lixo e desvio do caminho de esgotamento das fontes de recursos naturais. Contudo, para que as práticas sejam desempenhadas é necessário a internalização de novos hábitos de consumo e de atitudes em prol de um consumo mais consciente.

\section{Satisfação das necessidades humanas: os satisfatores}

As necessidades humanas percebidas são social e culturalmente determinadas. Logo, para ocorrer mudança de comportamento pautada no desenvolvimento sustentável deve-se recorrer à promoção de valores que estimulem padrões de consumo que estão dentro dos limites do que é ecologicamente possível, onde todos podem razoavelmente aspirar (WCED, 2018). Assim, pode-se afirmar, de forma ampla, que ser sustentável é ser capaz de satisfazer as necessidades dentro das limitações ecológicas. Entretanto, faz-se necessário entender o que se quer dizer por necessidades.

A necessidade é considerada a falta ou carência de coisas que são indispensáveis para a manutenção de uma vida. $\mathrm{O}$ que é necessário para sustentar uma vida não é uma questão supérflua. Deste modo, dentro desse contexto, "as necessidades humanas fundamentais são finitas, poucas e classificáveis [...] são as mesmas em todas as culturas e em todos períodos históricos" (Max-Neef, 1992, p. 199-200), assim, o que se altera são os modos ou meios empregados para satisfazê-las. O que Max-Neef chamou de satisfatores.

A satisfação das necessidades essenciais depende, em parte, de alcançar pleno potencial de crescimento econômico. Dentro disso, o desenvolvimento sustentável requer o crescimento da economia em lugares onde essas necessidades não estão sendo atendidas. Mas o crescimento por si só não é suficiente. Altos níveis de atividade produtiva e pobreza generalizada podem coexistir, essa relação põe em risco a natureza. Deste modo, o desenvolvimento sustentável requer que as sociedades satisfaçam as necessidades humanas pelo aumento do potencial produtivo assegurando oportunidades iguais para todos e preservando o ambiente ecológico (WCED, 2018).

Não apenas as necessidades humanas fisiológicas, também chamadas quantitativas, precisam ser atingidas. As necessidades consideradas intangíveis ou qualitativas, relacionadas ao bem-estar, como a família, segurança e a educação superior, também são alvo do desenvolvimento sustentável (Bolis et al., 2014). Entretanto, o relatório Nosso Futuro Comum não especifica como as nações podem alcançar um padrão de desenvolvimento das necessidades humanas de forma que se obtenha uma sociedade mais sustentável.

Os estudos de Manfred Max-Neef dão um suporte para essa lacuna. Para o autor, as necessidades humanas são inter-relacionadas e interativas. Isso significa dizer que, com a única exceção da necessidade mais básica de todas, a de subsistência, relacionada a tendência dos seres humanos em manter-se vivo, não existem hierarquias dentro do sistema (Max-Neef, 1992). Ao contrário de autores como Abraham Maslow (Teoria da Hierarquia das Necessidades Humanas) e Frederick Herzberg (Teoria dos Dois Fatores de Herzberg) Max-Neef propõe simultaneidades, complementaridades e trade-offs, como características do processo de satisfação das necessidades, em sua matriz de necessidades humanas

Essa perspectiva permite reinterpretar o entendimento de pobreza, muito limitado e restrito, uma vez que se refere exclusivamente aos problemas pessoais classificados abaixo de um certo limite de renda. Por se tratar de um conceito estritamente econômico, Max-Neef prefere falar não de pobreza, mas de pobrezas, onde qualquer necessidade humana fundamental, que não seja adequadamente satisfeita, revela uma pobreza humana.

Max-Neef (1992) classifica as necessidades humanas em nove categorias principais que incluem: subsistência (que precisam de comida, água, abrigo), proteção (um lugar seguro para viver, segurança social), participação (sendo parte de decisões que afetam a nossa vida), lazer (algum tempo livre e relaxante), afeição (que precisam de 
amigos, amor), a compreensão (aprendizagem, meditação), criação (cozinhar, projetar, inventar), identidade (um sentimento de pertencimento, conhecer a si mesmo) e liberdade (sendo capaz de escolher o modo como vivemos nossas vidas).

Estas necessidades acontecem simultaneamente, com exceção das necessidades de subsistência, e podem se complementar ou substituir uma a outra, dependendo de como elas estão sendo satisfeitas. Essa visão vai além das necessidades ambientais e de recursos financeiros, reconhece que existem vários tipos de necessidades humanas em que os seres humanos vivem, inclusive as sociais. $\mathrm{O}$ acúmulo de materiais físicos, reproduzidos pelo consumo exagerado, suprem algumas necessidades humanas relacionadas aos aspectos físicos, mas pouco atendem às necessidades psicossociais. Nesse sentido que Max-Neef (1992) propõe essas nove categorias, aos quais intitula escala humana de desenvolvimento.

\subsection{Orientação individualista- coletivista em direção a um modelo sustentável}

O desenvolvimento sustentável implica mudar a perspectiva humana de individual para coletiva na tomada de decisões, embasada em valores humanos e éticos, pois as consequências de decisões tomadas por alguns indivíduos podem ser percebidas por outros que não foram sequer consideradas neste processo. Isso significa que quaisquer ações precisam passar pela reflexão do impacto coletivo. Essa interdependência torna mais difícil de definir soluções eficazes para problemas do desenvolvimento sustentável. Nesse contexto, são considerados, tanto a intensidade de preocupação atribuída aos recursos naturais utilizados para o desenvolvimento da sociedade, quanto o grau de coletividade nas decisões sobre o uso destes recursos. Deste modo, tem-se os objetivos norteando as ações.

As orientações culturais de valor (individualista-coletivista) são determinantes para o alcance dos objetivos. Para objetivos mais sustentáveis, que são a redução dos impactos sociais e ambientais, é necessário um trabalho em conjunto onde a coletividade se baseia em valores e normas compartilhados entre indivíduos unidos por objetivos, interesses e/ou compromissos mútuos (Earley \& Gibson, 1998).

A ação humana oscila em um contínuo entre bem-estar socioeconômico e preocupações igualitárias com preocupações ambientais (Hopwood et al., 2005). Nas pessoas com consciência mais coletiva, essa ação tenta equilibrar seu a satisfação das suas necessidades imediatas com o bem-estar dos outros e da natureza, em uma perspectiva de curto, médio e longo prazos. Logo, quanto mais orientado para o grupo, o ser humano estiver, mais propenso ao desenvolvimento sustentável ele está.

\section{ASPECTOS METODOLÓGICOS Modelo conceitual e técnicas de coleta e análise de dados}

A partir das revisões teóricas anteriores, foi possível criar um modelo conceitual que representasse a base da presente pesquisa, como orientação para a coleta de dados. A Figura 1 representa os construtos identificados que podem contribuir com o Desenvolvimento Sustentável.

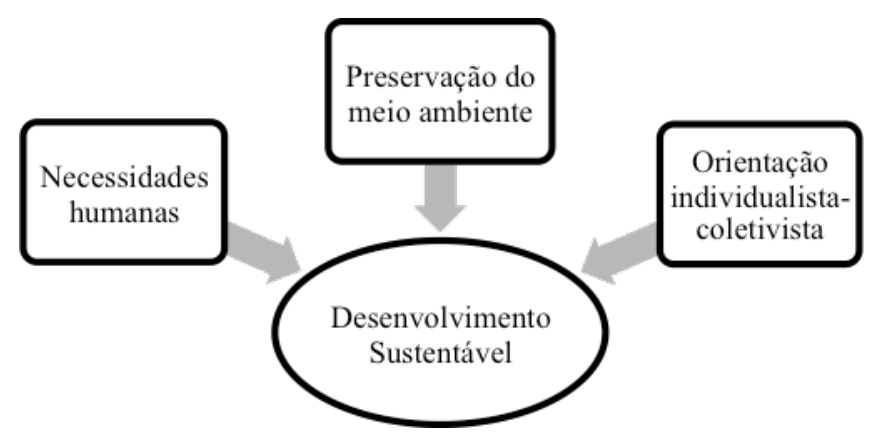

Fonte: Elaborado pela autora.

Figura 1: Modelo Conceitual

Para alcançar os objetivos propostos: a) identificar quais satisfatores são encontrados com relação as necessidades humanas; b) levantar aspectos de preservação dos recursos naturais 
encontrados; e c) avaliar a orientação individualista-coletivista, realizou-se um estudo de caso com uma plataforma de consumo colaborativo brasileira, Bliive. Tais objetivos foram selecionados considerando desenvolvimento sustentável como aquele que busca atender as necessidades do presente (satisfatores das necessidades humanas) sem comprometer (preservação dos recursos naturais) a habilidade das futuras gerações de atender suas próprias necessidades (orientação individualistacoletivista).

A coleta de dados compreendeu duas etapas. A primeira envolveu o levantamento de dados qualitativos, através de entrevistas com consumidores/participantes e um gestor do Bliive. As entrevistas ocorreram com auxílio de um roteiro pré-definido com base nas categorias destacadas no Quadro 1.
Para encontrar os consumidores do Bliive foi necessário criar um perfil na plataforma. Como pré-requisito, buscou-se usuários que tivessem realizado várias trocas. Entrou-se em contato com cada um deles pedindo para participar da pesquisa. Foram contatados 15 usuários de todo o país, destes, nove atenderam ao chamado do pesquisador, incluindo um dos sócios fundadores Roberto Pompeu.

$\mathrm{Na}$ sequência, foi aplicado um teste quantitativo para mensuração a atitude ambiental e orientação individualista-coletivista de valor cultural dos consumidores, com escalas já validades em estudos prévios (Quadro 1). Esta etapa buscou conhecer um pouco mais dos respondentes, com vistas a reduzir o viés de respostas socialmente aceitas. Ambas etapas ocorreram entre os meses de maio e junho de 2016.

\begin{tabular}{|l|l|c|c|}
\hline \multicolumn{1}{|c|}{ Aspectos } & \multicolumn{1}{|c|}{ Objetivo } & Fonte & Autor \\
\hline Meio ambiente & $\begin{array}{l}\text { Analisar de que forma a iniciativa e o } \\
\text { usuário promovem a proteção do meio } \\
\text { ambiente e a redução do consumo } \\
\text { (aumento do ciclo de vida do produto e 3 } \\
\text { R's - reduzir, reutilizar, reciclar) } \\
\text { Atitude ambiental (identificar atitudes } \\
\text { ecocêntricas, antropocêntricas ou } \\
\text { apáticas). }\end{array}$ & $\begin{array}{c}\text { Consumidores, } \\
\text { gestor e site }\end{array}$ & $\begin{array}{c}\text { Lei No 12.305/agosto de } \\
2010 \\
\text { Thompson e Barton } \\
\text { (1994) }\end{array}$ \\
\hline $\begin{array}{l}\text { Necessidades } \\
\text { humanas }\end{array}$ & $\begin{array}{l}\text { Avaliar a satisfação das necessidades } \\
\text { humanas (subsistência, proteção, afeição, } \\
\text { entendimento, participação, lazer, } \\
\text { criação, identidade, liberdade) }\end{array}$ & $\begin{array}{c}\text { Consumidores, } \\
\text { gestor e site }\end{array}$ & Max-Neef (1992). \\
\hline $\begin{array}{l}\text { Orientação } \\
\text { individualista- } \\
\text { coletivista }\end{array}$ & $\begin{array}{l}\text { Avaliar a orientação individualista- } \\
\text { coletivista, baseada na orientação cultural } \\
\text { de valor. }\end{array}$ & Consumidores & Chan, Yim and Lam \\
(2010).
\end{tabular}

Fonte: Elaborado pela autora.

Quadro 1: Categorias para coleta de dados

Os dados das escalas de atitude ambiental e Orientação de Valor foram analisados quantitativamente, através de médias (estatística descritiva básica), e utilizados para complementar os resultados encontrados nas entrevistas. Destaque-se que alguns dos entrevistados não responderam ao questionário. $\mathrm{O}$ que, de qualquer forma, não interfere de forma expressiva nas análises, visto que não foram aplicados à uma amostra significativa, nem se pretendia comparar as respostas de respondentes. O objetivo dessa etapa era conhecer os respondentes, complementando as entrevistas.
$\mathrm{Na}$ sequência, os dados foram sintetizados para concluir de que forma o consumo colaborativo se relaciona com o desenvolvimento sustentável. Nesse momento os impactos com relação às necessidades humanas e meio ambiente foram avaliados.

Foram realizadas oito entrevistas, sete com participantes e uma com um dos sócios fundadores do Bliive. Os nomes dos entrevistados foram alterados para preservar suas identidades, com exceção do sócio fundador Roberto Pompeu. Os entrevistados atenderam ao chamado dos pesquisadores, por meio da própria plataforma, 
onde se solicitou colaboração para a realização de uma pesquisa acadêmica.

$\mathrm{Na}$ sequência, apresenta-se o perfil dos entrevistados.

\section{Perfil dos entrevistados}

Claudino é um professor universitário, com doutorado, que desenvolve atividades ligadas ao desenvolvimento espiritual, tem 49 anos, é casado e sem filhos. Carlos é escrevente técnico judiciário, tem graduação em Direito e é solteiro e sem filhos. Maritza é representante comercial, formada em Engenharia Civil, dá aulas de Yoga, e é embaixadora do Bliive. Márcio está com 33 anos, é analista e gestor financeiro e embaixador do Bliive. Mariana tem 26 anos, atua de forma autônoma em soluções linguísticas. Possui superior completo em Letras. Marcel, tem 32 anos e é designer de produto. Henrique tem 40 anos e é co-criador da empresa livre Baobbá Lab. É bacharel em Matemática e embaixador do Bliive. Roberto é sócio fundador do Bliive, professor universitário e advogado.

\section{Informações do Bliive}

Fundada em maio de 2013, por uma brasileira, o Bliive é um movimento que foca na troca de talentos, habilidades e conhecimentos entre pessoas, por meio de um banco de tempo. O Quadro 2 a seguir destaca informações sobre a plataforma.

\begin{tabular}{|l|l|}
\hline \multicolumn{1}{|c|}{ Informações } & \multicolumn{1}{c|}{ Bliive } \\
\hline O que faz & Plataforma social de troca de tempo \\
\hline Sócios & José Fernandes, Lorrana Scarpioni, Murilo Mafra e Roberto Pompeo \\
\hline Início das atividades & 2013 \\
\hline Funcionários (incluindo sócios) & 6 \\
\hline Investimento inicial & Nenhum \\
\hline Faturamento em 2015 & Não revelado \\
\hline Fonte: Projeto Draft (2016)
\end{tabular}

Quadro 2: Características do Bliive

O Bliive envolve uma plataforma online e funciona conectando pessoas que oferecem experiências para trocar com outras pessoas. Toda a negociação acontece entre os próprios usuários, onde a plataforma oferece o espaço online para a divulgação. Para realização da troca utiliza-se a moeda do site, o tempo, de forma que não existe envolvimento financeiro no Bliive, e sim a moeda virtual chamada timemoney.

Cada experiência é trocada por horas que podem ser utilizadas para adquirir uma nova experiência. Toda pessoa que quer ter acesso às experiências de outras pessoas precisa entregar seus timemoneys. Nenhuma experiência tem valor diferente por ser mais ou menos difícil. O argumento da plataforma é que o tempo é igual para todos e, por isso, a única forma de medir quantos timemoneys vale cada troca é o tempo necessário para a realização da troca.

\section{RESULTADOS ENCONTRADOS}

Em seu site o Bliive intitula-se uma rede colaborativa de troca de tempo. Seu principal objetivo é oferecer uma alternativa ao dinheiro, onde as pessoas podem oferecer seu tempo como moeda para a troca de experiências. O tempo, de acordo com o site, é visto como um bem universal, que ultrapassa barreiras, não se prende à matéria e é comum a todos. Nesse formato, a plataforma aproxima pessoas por meio do compartilhamento de experiências pessoais ou profissionais (Bliive, 2016).

\section{Preservação dos recursos naturais}

Como o desenvolvimento sustentável é atender as necessidades do presente considerando a preservação dos recursos naturais. Da perspectiva da preservação dos recursos ambientais pode-se avaliar o papel da empresa e o comportamento dos indivíduos.

Da perspectiva do Bliive nenhuma das ações desenvolvidas pela plataforma está relacionada com redução, reutilização ou reciclagem de recursos físicos. Seu objetivo é proporcionar serviços diversos para seus usuários. Numa análise no site, nenhuma menção é feita com relação à natureza ou ao esgotamento dos recursos do planeta. Em entrevista, o próprio gestor destaca que não percebe nenhuma preocupação com tais aspectos. Entretanto, alguns entrevistados 
mencionaram ter uma preocupação constante com os aspectos da natureza.

A partir dos resultados da pesquisa quantitativa buscou-se avaliar a atitude ambiental e orientação de valor cultural dos entrevistados, através da análise das médias. Dentro dos resultados encontrados, o Bliive pode atender uma série de necessidades listadas anteriormente que foram identificadas por pessoas que: tem atitudes ecológicas e consciência coletivista, de acordo com os questionários por eles respondidos.

As medias das categorias encontram-se no Quadro 3.

\begin{tabular}{|c|c|c|c|c|}
\hline Entrevistados & $\begin{array}{c}\text { Atitude } \\
\text { ecocêntrica* }\end{array}$ & $\begin{array}{c}\text { Atitude } \\
\text { antropocêntrica* }\end{array}$ & Atitude apática* & $\begin{array}{c}\text { Orientação } \\
\text { coletivista* }\end{array}$ \\
\hline Claudino & 4,6 & 2,8 & 1,8 & 3,7 \\
\hline Carlos & 4,0 & 2,9 & 1,4 & 3,0 \\
\hline Maritza & 4,1 & 3,0 & 2,0 & 2,2 \\
\hline Márcio & 4,8 & 2,9 & 1,1 & 3,3 \\
\hline Mariana & 4,6 & 2,9 & 1,6 & 2,2 \\
\hline Marcel & - & - & - & - \\
\hline Henrique & 5,0 & 2,8 & 1,1 & 3,7 \\
\hline
\end{tabular}

Fonte: Elaborado pela autora. Nota: * Média aritmética. Aplicou-se uma escala Likert de 5 pontos.

Quadro 3: Médias atitude ambiental e orientação individualista-coletivista

Complementou-se os dados qualitativos analisados com as atitudes mensuradas pela escala de Thompson e Barton (1994). Dos sete consumidores entrevistados, apenas um não respondeu ao questionário.

As atitudes pró meio ambiente, principalmente as que consideram a natureza como importante por si própria, independentemente da sua relevância para a sobrevivência do ser humano, salientaramse frente as demais. Todavia, nem a visão ecocêntrica nem antropocêntrica foram destacadas nas entrevistas. Embora algumas das experiências disponíveis para a troca na plataforma contemplem educação ambiental, permacultura (oferecidas por Henrique, por exemplo), dentre outras práticas relacionadas à sustentabilidade, os entrevistados não destacaram o Bliive como mecanismo para praticar um comportamento mais ecologicamente correto, nem como motivador ou fonte de benefícios.

Como o desenvolvimento sustentável não é apenas determinado pelos aspectos do meio ambiente, a orientação coletivista, refletida tanto numericamente quanto nas entrevistas, destaca com nitidez os aspectos relacionados ao social e às necessidades humanas.

\section{Necessidades humanas}

A proposta do Bliive é oferecer uma alternativa ao dinheiro, onde as pessoas podem oferecer seu tempo como moeda para a troca de experiências. Como o próprio Gestor da iniciativa diz, o tempo é uma moeda democrática, que todas as pessoas dispõem, o que possibilita que qualquer pessoa possa realizar trocas na plataforma. Algumas das necessidades humanas categorizadas por Max-Neef (1992), tais como participação, afeição, entendimento, proteção, identidade, liberdade e criação, podem ser satisfeitas.

Sobre a necessidade de participação percebe-se que a plataforma oferece satisfatores por ser democrática e permitir que qualquer pessoa possa ingressar, interagir e obter experiências diversas, inclusive aquelas pessoas que não têm dinheiro e que não possuem uma formação institucional, sem restrição de localização geográfica, na maior parte das vezes. Essa oportunidade tem o poder de contribuir com a redução da desigualdade social e econômica. Além disso, dá um passo na direção da necessidade de entendimento, que trata da aprendizagem e exploração de novos conhecimentos.

Outras portas que se abrem a partir da participação são sobre as necessidades de liberdade e de criação. Liberdade porque oportuniza protagonizar o próprio processo de aprendizagem e autodesenvolvimento. O sujeito se torna autônomo e comprometido consigo e com o próximo, já que é a engrenagem do processo de troca de experiência. Criação porque, para aqueles que buscam, permite testar novos mercados (empreendedorismo) e, até mesmo, desenvolver competências e uma outra profissão.

Com relação a necessidade afeição, identificouse satisfatores a partir do potencial encontrado que permite que as pessoas se conectem, estreitem 
laços e formem amizades. A confiança existente nas relações também leva ao estreitamento dos laços. Juntamente com esses laços, encontram-se satisfatores que levam à satisfação da necessidade de proteção e identidade. Proteção porque a comunidade permite que se faça algo pelo outro, ou seja, contribuir com as carências de outras pessoas, a partir das suas próprias habilidades e experiências. Identidade porque proporciona sentimento de pertencimento. Contudo, para suprir esta necessidade, o indivíduo precisa estar engajado e estar disposto a conhecer novas pessoas. O sentimento de pertencimento tem como requisito a partilha de valores entre os membros do grupo. Ainda, desenvolver-se pessoal e profissionalmente contribui com a satisfação da identidade, onde o sujeito dispõe ferramentas que atuam na direção do autoconhecimento.

\section{Orientação para a coletividade}

A orientação para a coletividade reflete um domínio de ações dentro do qual um indivíduo deve prosseguir, a fim de atingir os interesses e objetivos do coletivo. Ou seja, implica preocupações além da perspectiva humana individual, sendo requisito para o desenvolvimento sustentável, conforme Bolis et al. (2014).

Entretanto, surgem situações em que os indivíduos podem ganhar mais por não contribuir com o grupo, exercendo o "free-riding" sobre as contribuições dos outros. Se os indivíduos sempre agem em seu próprio interesse, afigura-se impossível atingir o desenvolvimento sustentável.

Alguns entrevistados destacaram a preocupação com o outro como motivador para adentrar na plataforma e as médias de orientação de valor individualista-coletivista indicaram uma tendência ao coletivismo.

\section{Consumo Colaborativo impactando o desenvolvimento sustentável}

Duas formas de relacionar consumo colaborativo com desenvolvimento sustentável emergiram das análises. Uma centrada na gestão organizacional, quando ações são tomadas para que os consumidores se tornem mais conscientes e compactuem com objetivos que permitam essa alteração de paradigma de desenvolvimento. Outra, localizada nas percepções e comportamento do agente, que busca novas alternativas de consumo.

Com base nos dados apresentados, as organizações colaborativas têm potencial de contribuir com os desafios do desenvolvimento sustentável, a partir de algumas práticas, bem como seus participantes (consumidores) através do seu comportamento.

Sobre a satisfação das necessidades humanas, identificou-se que os free riders, que são aqueles querem apenas obter os benefícios da colaboração e não pensam em se comprometer com grupo (Olson, 1965), precisam ser evitados. Logo, criar mecanismos para proteger-se de consumidores que apostem na vantagem individual em detrimento do grupo favorece $\mathrm{o}$ coletivismo $\mathrm{e}$ fomenta $\mathrm{o}$ desenvolvimento do consumo colaborativo. Enquanto os objetivos forem apenas individuais, o sentimento de comunidade não pode se desenvolver e proporcionar que mais necessidades humanas possam ser satisfeitas. Da mesma forma, pode-se proceder com o aumento de possibilidades de conexões entre os consumidores, promovendo a conscientização dos mesmos, visto que estas conexões se mostraram relacionadas com as necessidades humanas.

Por se tratar de um modelo descentralizado (peer-to-peer), as relações entre os pares de consumidores permitiu contato mútuo e colaboração, proporcionando que estes consumidores façam parte da cadeia de fornecimento, distribuição e consumo.

Um dos objetivos da organização colaborativa, de acordo com o referencial teórico estudado, deve prever, de alguma forma, alguma ligação com os aspectos relacionados à preservação dos recursos naturais ou redução dos impactos das ações humanas no meio ambiente. $\mathrm{O}$ Bliive não demonstrou essa motivação relacionada aos aspectos ecológicos. Nesse momento vale o questionamento desse pré suposto: Será que o consumo colaborativo é uma alternativa ao desenvolvimento sustentável?

Além do objetivo principal do Bliive, realização de trocas, pode-se fomentar o desenvolvimento sustentável aproveitando as atitudes pró meio ambiente existentes entre os consumidores e incentivar o comportamento decorrente. Como visto, o comportamento dos agentes é fundamental para que haja mudança em direção de uma sociedade mais sustentável (Earley \& Gibson, 1998; Hopwood et al., 2005; Leff, 2011), logo uma organização colaborativa, como o Bliive, pode aproveitar das experiências disponíveis tais como educação ambiental, conceitos e dicas sobre permacultura, meio ambiente dentre outras, para incentivar um novo comportamento. Esse incentivo pode ser fundamental para a identificação dos consumidores com a plataforma, através do 
compartilhamento de valores pessoais com organizacionais.

Por fim, um aspecto base para o Desenvolvimento Sustentável é a preocupação com as gerações futuras, ou seja, outras pessoas que fazem parte da sociedade atual ou que farão parte da sociedade no futuro. Essa preocupação está presente nas pessoas que destacam consciência mais coletiva pois, para alcançar objetivos mais sustentáveis, é necessário um trabalho em conjunto de pessoas que compartilham valores, objetivos, interesses e compromissos (Earley \& Gibson, 1998). Quanto mais orientado para o grupo, o ser humano estiver, mais propenso ao Desenvolvimento Sustentável ele estará. Assim, incentivar a conexão entre os consumidores pode promover maior contato, fomentar empatia, respeito ao próximo e formação do sentimento de comunidade.

Promoção da participação em outras formas de consumo colaborativo também é relevante, visto que existem organizações que promovem mais os impactos sociais e outras mais os ambientais. Consumidores mais engajados tenderão a participar de mais organizações colaborativas.

$\mathrm{O}$ Caso Bliive não contemplou todos os requisitos ambientais necessários para promover alterações dos padrões de consumo e, por conseguinte, ir ao encontro do desenvolvimento sustentável de forma completa.

Embora as atitudes dos consumidores tenham sido pró meio ambiente, este aspecto não foi identificado nas entrevistas, na análise do site, nem nos objetivos do Bliive. Todavia, por haver engajamento com outras formas de consumo colaborativo e por preservarem orientação de valor mais coletivista é possível que essa atitude seja manifestada em outros contextos.

\section{CONSIDERAÇÕES FINAIS}

Ao estudar o Bliive e alguns de seus consumidores, pode-se visualizar uma aproximação empírica entre os temas de Consumo Colaborativo e Desenvolvimento Sustentável. Entendendo desenvolvimento sustentável como aquele que atende às necessidades das gerações atuais sem comprometer a possibilidade destas gerações futuras em atender às suas próprias necessidades. Com visto nos dados analisados, essa aproximação foi percebida mais fortemente quando se fala na satisfação das necessidades humanas e na preocupação com as gerações futuras, todavia ficando a preservação dos recursos naturais menos aflorada. Segue um resumo dos aspectos identificados:

\begin{tabular}{|c|c|c|}
\hline $\begin{array}{c}\text { Satisfatores encontrados com } \\
\text { relação as necessidades } \\
\text { humanas }\end{array}$ & $\begin{array}{c}\text { Preservação dos recursos } \\
\text { naturais }\end{array}$ & $\begin{array}{c}\text { Orientação individualista- } \\
\text { coletivista }\end{array}$ \\
\hline $\begin{array}{c}\text { Participação, afeição, } \\
\text { entendimento, liberdade, criação, } \\
\text { proteção e identidade. }\end{array}$ & $\begin{array}{c}\text { As atitudes pró meio ambiente } \\
\text { presentes, entretanto não foi } \\
\text { identificado nas entrevistas. }\end{array}$ & $\begin{array}{c}\text { Coletivismo - Os consumidores } \\
\text { apresentam orientação de valor } \\
\text { mais coletiva que individualista. }\end{array}$ \\
\hline
\end{tabular}

Fonte: Elaborado pela autora.

Quadro 4: Resumo dos dados encontrados

Embora a orientação cultural de valor dos entrevistados seja coletivista e as atitudes pró meio ambiente sejam positivas pouco se faz para que a preservação dos recursos naturais seja percebida. Satisfazer as necessidades humanas, conforme citado no Quadro 4, é muito mais frequente no caso estudado. Logo, o Bliive não demonstrou práticas relacionadas aos aspectos ecológicos. Dessa forma, o questionamento: Práticas de consumo colaborativo são formas de contribuir com o desenvolvimento sustentável? Nessa plataforma de troca de tempo estudada a resposta é não.

A análise de um único caso traz limitações. A mais notória relaciona-se à limitação da pesquisa qualitativa, a impossibilidade de generalização dos resultados. Todavia é um primeiro esforço na compreensão desse contexto de consumo colaborativo que tem se tornado cada vez mais comum no mercado e que requer atenção dos pesquisadores. Outra limitação refere-se à quantidade de entrevistados, que não representam a população de participantes do Bliive. Como os entrevistados responderam ao chamado dos pesquisadores, pressupõe-se que já apresentam alguma inclinação para colaboração. Logo, obter mais entrevistas e analisar outros casos, com diferentes características pode contribuir fortemente no entendimento do consumo colaborativo, como um modelo de negócios mediado pelas tecnologias de informação e comunicação que tem ganhado escala mundial. 
Pesquisas futuras com diferentes casos podem contribuir teoricamente com o crescimento da literatura sobre o tema, no que concerne ao conceito de consumo colaborativo e às diferentes organizações existentes no mercado.

\section{REFERÊNCIAS}

Albinsson, P. A., \& Perera, Y. (2012). Alternative marketplaces in the 21 st century: building community through sharing events. Journal of Consumer Behaviour, 11, 303-315.

Albinsson, P. A., Wolf, M., \& Kopf, D. (2010). Anticonsumption in East Germany: Consumer resistance to hyperconsumption. Journal of Consumer Behaviour, 9(6), 412-425.

Belk, R. W. (2007). Why not share rather than own? American Academy of Political and Social Science, 611(126).

(2010). Sharing. Journal of Consumer Research, 36, 715-734.

(2014) You are what you can access: Sharing and collaborative consumption online. Journal of Business Research, 67, 1595-1600.

Black, I. R., \& Cherrier, H. (2010). Anti-consumption as part of living a sustainable lifestyle: daily practices, contextual motivations and subjective values. Journal of Consumer Behaviour, 9(6), 437-453.

Bliive. Recuperado em 14 maio 2016 de http://bliive.com.br.

Bolis, I., Morioka, S. N., \& Sznelwar, L. I. (2014). When sustainable development risks losing its meaning: Delimiting the concept with a comprehensive literature review and a conceptual model. Journal of Cleaner Production, 83, 7-20.

Botsman, R., \& Rogers, R. (2011). O que é meu é seu: como o consumo colaborativo vai mudar o nosso mundo. Porto Alegre: Bookman.

Brasil. Lei $N^{o}$ 12.305, de 2 de agosto de 2010. Recuperado em 12 abril, 2018 de http://www.planalto.gov.br/ccivil_03/_Ato20072010/2010/Lei/L12305.htm

DeMenezes, U. G. (2016). Desenvolvimento sustentável e economia colaborativa: um estudo de múltiplos casos no Brasil. Tese de Doutoramento não publicada, Escola de Administração, Universidade Federal do Rio Grande do Sul, Porto Alegre, Brasil.

Drexhage, J., \& Murphy, D. (2010). Sustainable development: from Brundtland to Rio 2012. International Institute for Sustainable Development (IISD). United Nations Headquarters, New York.

Earley, C., \& Gibson, C.B. (1998). Taking stock in our progress on individualism-collectivism: 100 years of solidarity and community. Journal of Management, 24(3), 265-304.

Hamari, J., Sjöklint, M., \& Ukkonen, A. (2016). The sharing economy: Why people participate in collaborative consumption. Journal of the Association for Information Science and Technology, 67(9), 2047-2059.

Hopwood, B., Mellor, M., \& O’brien, G. (2005). Sustainable development: mapping different approaches. Sustainable Development, 13, 38-52.

IBICT. Instituto Brasileiro De Informação em Ciência e Tecnologia. Recuperado em 11 abril, 2018 de http://www.ibict.br/inclusao-social-epopularizacao-da-ciencia/avaliacao-do-ciclo-devida-de-produtos-e-sistemasprodutivos/apresentacao/?searchterm $=$ ciclo $\% 20 \mathrm{~d}$ e\%20vida\%20do\%20produto.

Jansson, J., Marell, A, \& Nordlund, A. (2010). Green consumer behavior: determinants of curtailment and eco-innovation adoption. Journal of Consumer Marketing, 27(4), 358-370.

Kayo, E. K., Kimura, H., Martin, D. M. L., \& Nakamura, W. T. (2006). Ativos intangíveis, ciclo de vida e criação de valor. Revista de Administração Contemporânea, 10(3), 73-90.

Leff, E. (2001). Saber ambiental: sustentabilidade, racionalidade, complexidade, poder. Petrópolis RJ: RJ, Vozes/PNUMA.

Max-Neef, M. (1992). Development and Human Needs. In: Ekins, P., \& Max-Neef, M. (Eds). Real Life Economics: understanding wealth creation. London: Routledge, 197-213.

Mebratu, D. (1998). Sustainability and sustainable development: historical and conceptual review. Environment Impact Asses Review, 18, 493-520.

Olson, M. (1965). The logic of collective action: public goods and the theory of groups. Cambridge, MA: Harvard University Press.

Ozanne, L. K., \& Ballantine, P. W. (2010). Sharing as a form of anti-consumption? An examination of toy library users. Journal of Consumer Behaviour, 9, 485-498.

PNUD. Programa das Nações Unidas para o Desenvolvimento. Recuperado em 10 abril, 2018 de http://www.pnud.org.br/ODS12.aspx

Sparks, P., \& Shepherd, R. (1992). Self-identity and the theory of planned behavior: assessing a role of identification with "green consumerism". Social Psychology Quarterly, 55(4), 388-399.

Stokes, K., Clarence, E., Anderson, L., \& Rinne, A. (2014). Making sense of the UK collaborative economy. Recuperado em Acesso em 8 de April, 2015 , de https://www.nesta.org.uk/sites/default/files/maki ng_sense_of_the_uk_collaborative_economy_14 .pdf.

Thompson, S. C. G., \& Barton, M. A. (1994). Ecocentric and anthropocentric attitudes toward 
the environment. Journal of Environmental Psychology, 14, 149-157.

WCED. (2018). Report of the World Commission on

Environment and Development: Our Common
Future. Recuperado em 10 abril, 2018 de http://www.un-documents.net/wced-ocf.htm

\title{
Collaborative consumption: Is it a path to sustainable development?
}

\begin{abstract}
Among the various proposals to reduce the negative impacts caused by man to the planet has recently stood out the collaborative consumption. This can be defined as a business model mediated by information and communication technologies that is based on the collaboration of suppliers and consumers (De Menezes, 2016). Based on this context, this study aimed to empirically identify the relationship between collaborative consumption and sustainable development based on the following emphases: human needs, resource preservation and cultural orientation of value. For this, a case of a virtual community of time interchange (Bliive) was studied. Data were collected from users, from one of the managers and from Bliive's own website. The results obtained allow us to observe only a certain relation between the themes, since Bliive did not contemplate all dimensions of sustainable development (human needs, preservation of the environment and concern for the future). This was due to the environmental aspects necessary to promote changes in consumption patterns that were not included in the results. The emphasis is given to the dimension of social aspects related to the satisfaction of human needs, such as participation, affection, understanding, protection, identity, freedom and creation, and, finally, the orientation to the community was highlighted.
\end{abstract}

Keywords: Sustainable development, Collaborative consumption, Bliive. 